\title{
EVALUATION OF THE EFFECT OF RURAL ROAD \\ CONDITION ON AGRICULTURAL PRODUCE TRANSPORTATION
}

Final version submitted on 5 November 2014

Word count: $\quad 4671$ words; 9 Figures; 2 Tables

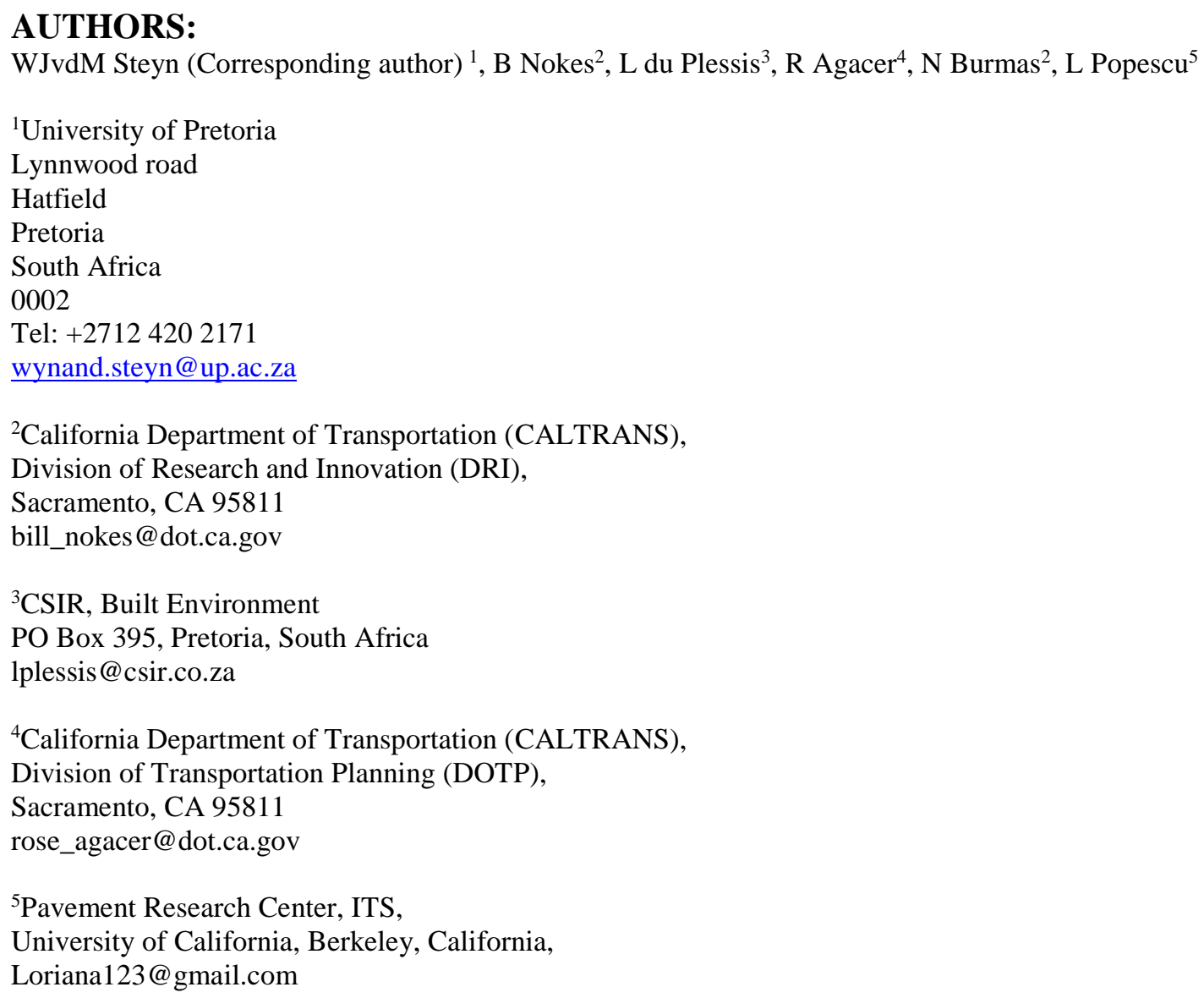




\begin{abstract}
Road condition affects the operations and costs of vehicle using the infrastructure. Various Vehicle Operating Cost (VOC) models provide an indication of road roughness effects on fuel consumption, additional damage to vehicle and tire wear. These models do not include the effect of road conditions on the condition and potential damage of transported freight. These potential damages are mostly limited through the use of improved vehicle technologies or packaging. In the agricultural transportation situation, it is often found that packaging is not a solution to the problem as the use of older vehicle technology operated on mostly rural roads with lower riding quality levels is a main contributor to the problem. This paper evaluates the quantified effects of riding quality on low volume roads on selected damage levels of tomatoes in California. The paper is partly based on a study focusing on Vehicle-Pavement Interaction and its effects on the broader California economy. Vehicle responses to road conditions were measured during operations on a range of rural routes. Laboratory experiments were developed to replicate the dominant vibrations of the trucks, and to measure the stresses that tomatoes typically undergo at these vibration levels. The damage and failure levels for the tomatoes during transportation were determined, and these damage levels used to calculate typical costs to the agricultural suppliers due to road conditions. The problem could thus be quantified, and input data provided for a cost/benefit evaluation of the potential maintenance/improvement of the various routes typically used to transport the tomatoes.
\end{abstract}




\section{INTRODUCTION}

A pilot study was conducted for the California Department of Transportation (CALTRANS) where principles of Vehicle-Pavement Interaction (V-PI) and state-of-the-practice tools were used to simulate and measure loads and accelerations of trucks and their freight on a selected range of typical pavement surface profiles on the State Highway System in the San Joaquin Valley. The project focused on determining economic effects of road conditions and to provide a basic understanding to CALTRANS of private sector decisionmaking in road freight transportation. The comprehensive set of interactions between the efficiency and efficacy of road freight transportation and the capacity, performance and regulation of road infrastructure, in the state could be identified and described. The overall objective of the project was to enable CALTRANS to manage the risks of decisions regarding freight and the management and preservation of the pavement network in an improved way as the potential effects of such decisions will be quantifiable in economic terms. This paper focuses on one specific aspect of the study, which is to indicate how the riding quality of low volume rural roads can affect the vehicle and cargo damage of agricultural produce, based on the collected data and analyses.

\section{STUDY BACKGROUND}

Freight transport, and specifically truck transport is crucial to California, the home of the US's largest container port complex and the world's fifth largest port. Truck-based transportation dominates the freight transportation scene in California with $82 \%$ of the freight tons shipped from California utilizing trucks. There are over 2700 lane-miles of truck routes in the San Joaquin Valley region, with over $80 \%$ designated Surface Transportation Assistance Act (STAA) National Truck Routes. Farm products are the dominant commodity carried outbound from the San Joaquin Valley, comprising $33 \%$ of the total outbound movements, consisting of fresh field crops. The region accounts for over $8 \%$ of the total Gross Domestic Product (GDP) for the state of California. The San Joaquin Valley includes six of the top 10 counties in California for total agricultural production (1).

Planning and making informed decisions about freight transported by trucks on the State Highway System requires reliance on data and information that represent (inter alia) pavement, truck, and freight interactions under conditions as they exist in California. Currently, a national freight policy is expected in the next federal transportation reauthorization bill, and CALTRANS already has several freight initiatives in progress including a scoping study of the California Freight Mobility Plan (CFMP) and planning for the Statewide Freight Model. These along with other plans will support the California Transportation Plan that will be updated by December 2015. Data and information obtained in the pilot study are needed for evaluations, plans, and decisions to help meet requirements of legislation. The overall scope of this project entails the tasks shown in Table 1 and are discussed in the various project reports and outside the scope of this paper $(1,2,3,4$, $5)$. Figure $1(1,6)$ indicates the broad scope of the potential effects of road riding quality on the broader transportation economy. In the larger project, all aspects indicated in Figure 1 are addressed.

Two companies voluntarily participated in the project. Both companies were selected based on contacts made with private industry to obtain interested parties that were willing to cooperate with CALTRANS in this project. The focus of this paper is on Company A whose primary business is the production of a range of bulk agricultural products. In order to protect the confidentiality of the information, anonymous designations are used for the routes for Company A and no maps with routes are shown.

The outputs from the pilot study are expected to be used as input towards planning and economic models to enable an improved evaluation of the freight flows and costs in the region. It is anticipated that use of findings from the pilot study as input by others into planning and economic models will enable calculating the direct effects of riding quality (and therefore road maintenance and management efforts) on the regional and state economy.

The riding quality of a road is used as the primary indication of the quality of a road - mainly due to findings that the most of the deterioration in the road structure ultimately translates into a decrease in the riding quality of the road. Various studies about the effect of the riding quality of roads on the vibrations and responses in vehicles have been conducted. The main conclusions indicate that a decrease in the riding quality of a road is a major cause of increased vibrations and subsequent structural damage to vehicles and cargo (7, 8, 9, 10, 11, 12). These increased vibrations and structural damage to vehicles can potentially have many negative effects on the transportation cost of companies and the broader economy. Comparing the estimated annual road maintenance costs per kilometer with the potential savings in VOC shows significant benefits that can be realized when keeping the road in good condition (13). The vertical acceleration experienced when travelling over rough road surfaces is what causes damage to vehicles, increased wear and tear and, potentially, damages to and loss of transported cargo. A good understanding of the State Highway System pavement conditions in terms of riding quality in California exists, as well as major truck types and operational conditions on these pavements. The major commodities being transported have been identified, and the potential links with models such as the Cal-B/C models clarified. With this background to the study, the focus of this paper is specifically on the measured accelerations inside the trucks and the resultant damage caused to the transported tomatoes. 


\section{CASE STUDY METHODOLOGY}

The objective of this part of the study (Task 8) was to measure typical vehicle response data from typical routes in California and to use this data to analyze VOCs and freight damage costs, all linked to riding quality. The methodology followed consisted of the following steps:

- Identification of Company A vehicles and routes;

- Identification of appropriate locations on the vehicles for measuring vertical accelerations;

- Measuring the vertical accelerations as well as the location and speed of the vehicle traveling over the selected route using stand-alone accelerometers (Figure 2). Accelerometers measured orthogonal accelerations and were rigidly attached to the selected locations;

- Validation of the collected data;

- Conducting a laboratory study to quantify the damage to the tomatoes at the measured acceleration levels, and

- Analysis of collected data in terms of effect of mainly road riding quality on the vertical accelerations on the vehicles and freight.

The primary data collected from the trucks and freight are vertical, horizontal and longitudinal accelerations, measured using off-the-shelf accelerometers. The focus of the analysis is on the vertical acceleration data. Vehicle location and road condition were monitored using a GPS and a video camera, while riding quality was calculated based on measured road profiles.

Company A transports agricultural freight, and specifically tomatoes. They operate a large fleet of trucks and run a well-designed and managed operation where the logistics of movements between the farms and processing plant is vital to ensure that the plant can function optimally. The typical truck used for the collection and transport of tomatoes and location of sensors are shown in Figure 2. These are CA Legal Double - Type 11 (2S1-2) trucks. Although the study limitations only allowed one truck to be instrumented for the pilot study, the similarity between the trucks, drivers, routes and freight allows the data to be viewed as representative of that for the company. Dual tires (size 11R22.5) are used on all axles except the steering axle with steel suspension for the trailers while the truck tractor uses air suspension. The freight for the study consisted of loose tomatoes destined for the processing plant. The routes center around the processing plant for Company A (Figure 3). It consists of a mixture of interstate, state highway and county roads, with limited farm roads involved. The same route was used for both an empty truck and a full load and the distances (Table 2). The findings of the pilot case study are only valid while the conditions remain constant (i.e. type of agricultural product, type of trucks and truck component, type of route).

Validation of the data obtained for Company A indicated that the dataset was reasonable to work with and that reasonable trends were visible in the data. In terms of the general trends observed, it was seen that rougher roads showed higher accelerations than smoother roads and the accelerations were higher on top of the loads than at the bottom of the loads. In Figure 4 typical accelerometer data (vertical, longitudinal and transverse) for the first trailer's second axle are shown for the full trip, starting as an empty trailer and finishing the trip fully loaded. The data indicate the higher accelerations expected when the trailer is empty than when it is fully loaded.

The standard data analysis procedure requires calculation of the dominant frequencies for each of the location using a Power Spectral Density (PSD) analysis (Figure 5). The bottom of Figure 5 shows the total area underneath the PSD curve which is used to provide an indication of the severity of the total movement at the specific location. Data indicate that the trailer axle on D road experienced the highest severity of accelerations, with the same axle on HM road having the lowest severity.

Figure 6 and Equation 1 show the average speeds attained on each of the sections of road with the full vehicle. Analysis of this data together with the riding quality of each of the road sections provide a relationship indicating that the speed of the trucks drops as the riding quality deteriorates. Although the relationship is based on only one trip, discussions with Company A confirmed that these were typical speeds on the route. All the road sections included in the analysis were long enough that the truck could keep to the speed that was safe for the driver to travel at, and there was no significant traffic on any of the roads that artificially affected the speed of the truck.

$$
\begin{array}{ll}
\text { Speed }[\mathrm{km} / \mathrm{h}]=-12.643(\mathrm{IRI}[\mathrm{m} / \mathrm{km}])+88.888\left(\mathrm{R}^{2}=0.88\right) & \text { Equation 1 (metric) } \\
\text { Speed }[\mathrm{mph}]=-0.1254(\operatorname{IRI}[\mathrm{inch} / \mathrm{mile}])+55.55 & \text { Equation 1 (US customary) }
\end{array}
$$

Measured accelerometer data for Company A agrees with the expected outcomes, showing increased variation and severity on rougher road sections than on smoother road sections. Selected locations on the trailer (positions furthest from the Center of Gravity $(\mathrm{CoG})$ ) showed higher severity than locations closer to the CoG. 


\section{EVALUATION OF RIDING QUALITY EFFECTS ON AGRICULTURAL PRODUCE}

Knowing that the riding quality affects the vehicle, and the transported cargo provide only part of the required outcome of the study, as the economic effects of the riding quality levels are far more important for the California economy. Relationships between riding quality and fuel consumption, tire wear, and additional repair and maintenance costs to the vehicle were used to calculate the effect of the different road sections on the costs for Company A. The relationships were sourced from (11). Relationships between the riding quality and tire loads, vertical accelerations and other parameters were developed specifically for the collected data. A detailed discussion of these parameters is outside the scope of this paper and is addressed in the original reports (3).

O'Brien et al. (14) indicated that various types of fruit can be damaged when vibrated at frequencies ranging from 9 to $54 \mathrm{~Hz}$, with specific bands of frequencies for different types of fruit. The frequency range of sensitivity for tomatoes is between 5 and $13 \mathrm{~Hz}$ with a mode of $10 \mathrm{~Hz}$. These frequencies fall in the range of the axle hop frequencies, which are typically between $5 \mathrm{~Hz}$ and $20 \mathrm{~Hz}$. The axle hop frequencies are often transposed to the fruit cargo inside of the packaging, especially in the case of bad truck suspension. A limited laboratory study was conducted to determine the potential damage that may be caused to transported tomatoes on the routes traveled by Company A. A laboratory experiment was conducted at the University of Pretoria (South Africa), in which the accelerations as experienced on the Company A vehicle were applied to a sample of tomatoes, while the contact stresses between the tomatoes are being measured. These data were analyzed and, together with recent fresh produce market prices from the Johannesburg Fresh Produce Market, used to estimate potential economic damage due to the condition of the routes on which Company A transports their tomatoes (similar cost data were not available for California at the time of the analysis).

It should be appreciated that this is a very limited study and that the objective was mainly to determine whether or not it is possible to obtain such information. In order to implement the outputs from this study wider, a larger sample of different types of tomatoes and routes will be required, as well as typical California market prices for tomatoes (or other sensitive fruits and vegetables). The methodology used for the determination of the potential damage on the tomatoes while being transported is as follows:

- Accelerations were measured at various locations on the load of tomatoes during transport over a range of roads. These accelerations provided an indication of the dominant frequencies and the severity of vibrations that the tomatoes experience while being transported;

- A laboratory setup was manufactured that allowed for placing around $40 \mathrm{~kg}$ of tomatoes inside a container on top of a vibrating table of which the dominant frequency can be selected. Flexible pressure sensors were placed in-between the tomatoes to measure the contact stresses that they exert on each other during vibration;

- The container of tomatoes was vibrated at a range of frequencies as obtained from the actual truck data, while measuring the pressures and accelerations;

- The stiffness (firmness) of the tomatoes was determined using a standard load / deflection test, of which the data were converted to stress / strain $(\sigma / \varepsilon)$ relationships;

- The damage limit of the tomatoes was defined as the stress when the stress/strain curve diverted from a linear-elastic relationship, and the failure condition as the stress where the tomatoes failed in the stress/strain test, and

- The data obtained from the pressure films inside the container of tomatoes were analyzed, and the range of contact stresses compared to the defined damage and failure conditions. A guideline was set to compare the $98^{\text {th }}$ percentile contact stress with the damage and failure stresses.

The stiffness of the tomatoes was measured for both relatively green and ripe tomatoes, and also for both major configurations (loading from top and loading from the side). The outcome of these tests showed clear groups of stiffness data (Figure 7). Comparison of these data sets with published tomato firmness data (15) showed relatively good similarity. Cumulative contact stresses measured in-between tomatoes during the tests at the various dominant frequencies are shown in Figure 8 (graph only shows 80 to $100 \%$ cumulative distribution data for clarity). The data indicate that the majority of the measured contact stresses were less than $5 \mathrm{kPa}$.

Analysis of the damage data as well as similar data for the $98^{\text {th }} \%$ damage levels, provided for development of a relationship between the road riding quality and the damage and failure levels for the specific truck transporting tomatoes (Figure 9). Up to this stage the procedure thus provides for evaluation of the expected damages that may be experienced by transported agricultural produce as the truck travels over roads of varying roughness or riding quality. Although there are a number of limitations in the current study, the process provides for the principles of an objective evaluation of these damages and should be adaptable to other agricultural produce too.

The process described provides for an objective evaluation of potential damage to transported agricultural produce on a range of roads. The following limitations to the current process and data set will be addressed in a follow-up study:

- $\quad$ Range of tomato types; 
- $\quad$ Ripeness of tomato;

- $\quad$ Speed effects - tests should be conducted at acceleration levels obtained at a range of speeds;

- Long duration trips - current laboratory tests were only conducted for 60 seconds, and the effects of shorter and longer trip durations should be evaluated, and

- Scaled model - current tests were conducted on a small sample of tomatoes; the potential effect of bulk tomatoes should be evaluated.

In order to develop a method for the incorporation of economic effects in the evaluation, a South African application of the process was conducted, as access was possible to actual market prices of tomatoes. The process to calculate the economic effect of the road conditions consisted of the following steps:

- Typical market volumes and prices of tomato sales for one market-day at the Johannesburg Fresh Produce Market were obtained (578 $000 \mathrm{~kg}$ of tomatoes);

- Prices per class of tomato were obtained. Tomato classes were related to the good, damaged and failed categories of tomatoes as obtained from the laboratory tests. An average price per tomato class was calculated to indicate the income expected for the day's produce. A good relationship was observed between the tomato class and price with lower class tomatoes having lower prices. Failed tomatoes were deemed not to sell at all, and the loss due to these tomatoes were calculated as the average price of all tomato classes, and

- The income for the tomatoes was calculated for the day, and the income if no tomatoes were damaged or failed was also calculated.

The outcome of this analysis was an indication that a loss of about $8 \%$ in income was generated due to tomatoes fetching lower prices (damaged) or not being sold at all (failed). It should be appreciated that tomato prices have a direct influence on this calculation, and also the volumes of tomatoes and distances for trucks to travel to and from the market (or processing plant). However, the process allows for an objective calculation rather than a guess of the potential damage caused by inadequate road conditions. The outcome of the analysis was discussed with various agricultural producers and associations, and they agreed with the general physical damage and damage cost levels obtained.

In terms of the use of this type of information to CALTRANS, it is suggested that such information (beyond what is possible to produce in a pilot study) could help in developing some form of freight performance measurement indicator(s). Performance measurement indicators might be a combination of the expected damage and failure of produce on the routes for a specific county or region, combined with the lower speeds that trucks typically travel on rougher routes to indicate the potential economic effects of the road network of which the roughness is less than optimal.

Further, the data obtained from such a study can be used (if extensive enough with a wider range of vehicles and routes) in defining policy around supply and maintenance of agricultural routes by road owners and agencies. The data provide for a quantifiable method to establish the additional cost of routes that are in an unacceptable condition. Road users can also use such data to conduct an evaluation of the level of maintenance costs that they can absorb through own contributions to ensure lower damage levels to their produce. Lastly, knowledge of the levels of road condition that are damaging to the produce in a certain region can lead to the development of an improved understanding of warning riding quality levels to be instituted in the Pavement Management System of the agency for managing road condition.

\section{CONCLUSIONS}

Based on the information provided in this paper the following conclusions are drawn:

- In situ vibrations on vehicles and transported agricultural produce were measured and related to riding quality;

- Actual contact stresses between tomatoes were measured objectively in a laboratory model at a range of acceleration levels observed on trucks operated on real routes and expressed as a percentage of damage / failure stresses based on the stiffness of the transported tomatoes;

- It is possible to relate the damage and failure levels to road condition and develop potential performance measurement indicators to be used in freight transport models, and

- It is possible to calculate benefit / cost ratios for the lower damage and thus losses of agricultural produce transported on roads before and after being maintained to improve their riding quality.

\section{RECOMMENDATIONS}

Based on the information presented in this paper it is recommended that: 
- CALTRANS continue with the development of performance measurement indicators incorporating the damage levels, economic aspects and speeds due to inadequate road condition, to enable economic benefits of improving road conditions to be modeled objectively, and

- Tests to continue to address limitations in terms of "California" tomatoes, trip duration, full-scale truck measurements using pressure sensors and tests on other potentially sensitive agricultural produce.

\section{ACKNOWLEDGEMENTS}

This work is based on the research supported mainly by CALTRANS and in part by the National Research Foundation of South Africa. The project team and NRF Grantholder acknowledges that opinions, findings and conclusions or recommendations ex-pressed in any publication generated by the CALTRANS and NRF supported research are that of the authors, and that CALTRANS and the NRF accept no liability whatsoever in this regard.

\section{REFERENCES}

1. Steyn, W.J.vdM., Viljoen, N, Popescu, L and Du Plessis, L. 2012a. Freight-Truck-Pavement Interaction, Logistics, \& Economics: Final Phase 1 Report (Tasks 1-6). Report UCPRC-RR-2012-06. FHWA No.: CA132482A.

2. Steyn, W.J.vdM., Monismith, C.L., Nokes, W.A., Harvey, J.T., Holland, T.J. and Burmas, N. 2012 b. Challenges confronting road freight transport and the use of vehicle-pavement interaction analysis in addressing these challenges. In Journal of the South African Institution of Civil Engineers, Vol 54, No. 1, pp. 14-21, April 2012, Pretoria, South Africa. ISSN 1021-2019.

3. Steyn, W.J.vdM. and Du Plessis, L. 2014. Freight-Truck-Pavement Interaction, Logistics, \& Economics: Final Phase 1 Report (Tasks 9-11). Report UCPRC-RR-2014-01.

4. Steyn, W.J.vdM. 2013. Freight-Truck-Pavement Interaction, Logistics, \& Economics: Final Phase 1 Report (Tasks 7-8). Report UCPRC-RR-2013-08.

5. Viljoen, N., van Heerden, Q., Mashoko, L. and van Dyk, E. 2013. Logistics augmentation to the FreightTruck-Pavement Interaction pilot study: Preliminary report. Summary Report No: UCPRC-RR-2014-02.

6. Steyn, W.J.vdM., Bean, W.L., King, D. and Komba, J. 2011. Evaluation of selected effects of pavement riding quality on logistics cost in South Africa, Transportation Research Record: Journal of the Transportation Research Board No. 2227, 3, pp. 138 - 145.

7. Singh, SP., John R. Antle and Gary G. Burgess. 1991. Comparison between lateral, longitudinal, and vertical vibration levels in commercial truck shipments. Packaging Technology and Science. Vol. 5, Issue 2, Pages $71-75$.

8. Slaughter, D.C., Thompson, J.F. and Hinch, R.T. 1998. Packaging Bartlett pears in polyethylene film bags to reduce vibration injury in transit, Transactions of the ASAE Vol. 41(1):107-114 @ 1998 American Society of Agricultural Engineers 0001-2351 / 98 / 4101-107.

9. Jarimopas, B. Singh, S.P. and Saengnil, W. 2005. Measurement and analysis of truck transport vibration levels and damage to packaged tangerines during transit. Packaging Technology and Science, Vol 18, March, pp. 179- 188.

10. Chonhenchob, V. Sittipod, S. Swasdee, D. Rachtanapun, P. Singh, S.P. Sing, J. 2009. Effect of truck vibrations during transport on damage to fresh produce shipment in Thailand. Journal of Applied Packaging Research, Vol. 3, No. 1, January, pp. 27-38.

11. Chatti, K and Zaabar, I, 2012. Estimating the effects of pavement condition on vehicle operating costs. National Cooperative Highway Research Program (NCHRP) 720. Transportation Research Board (TRB), Washington D.C.

12. SMTP. Source reduction by European test schedules, Final report, Contract no SMT4-CT95-2005 (DG12RSMT), 1999.

13. Steyn, W.J.vdM. and Bean, W.L. 2011. The potential effects of deteriorating road quality and maintenance in South Africa. In The Seventh Annual State of the Logistics Survey for South Africa, CSIR BE, Pretoria, South Africa. Ittmann, H., Havenga, J. and De Swart A. (Editors). pp. 30-35. ISBN 978-0-7988-5597-6.

14. O’Brien, M., Gentry, J.P., and Gibson, R.C. 1965. Vibrating characteristics of fruit as related to in-transit injury. Transactions of the ASAE. 8:241-243.

15. Sobotka, F.E., Watada, A.E. and Diener, R.G. Effectiveness of the pressure-load meter in measuring firmness of tomato fruit. Hortscience, Vol. 7(1). February 1972. 
TABLE 1 Major technical task description for the project

\begin{tabular}{|l|}
\hline \multicolumn{1}{|c|}{ Task description (only technical tasks are shown with their original task numbers) } \\
\hline Task 3: Inventory of current California riding quality data. \\
\hline Task 4: Inventory of current California vehicle population. \\
\hline $\begin{array}{l}\text { Task 5: Research/review available information resources and related efforts focusing on V-PI, logistics, } \\
\text { transportation economy. }\end{array}$ \\
\hline $\begin{array}{l}\text { Task 7: Simulation of selection of California trucks on selected routes/segments using calibrated V-PI } \\
\text { simulation software. }\end{array}$ \\
\hline $\begin{array}{l}\text { Task 8: Measurements of accelerations and damage on selected locations of selected California vehicles on } \\
\text { specific routes. }\end{array}$ \\
\hline Task 9: Develop map of road conditions, vehicle and freight parameters based on measured data. \\
\hline $\begin{array}{l}\text { Task 10: Development / calibrate simple relationships between the riding quality and the various measured } \\
\text { and simulated V-PI and damage. }\end{array}$ \\
\hline $\begin{array}{l}\text { Task 11: Explore potential links regarding the environmental impacts and construction riding quality } \\
\text { specifications for the selected region. }\end{array}$ \\
\hline
\end{tabular}


TABLE 2 Route details and riding quality

\begin{tabular}{|c|c|c|c|}
\hline \multicolumn{2}{|c|}{} & \multicolumn{2}{c|}{ Riding quality (IRI) [m/km] (inch/mile) } \\
\hline Road & Distance $[\mathbf{k m}]($ mile) & Empty route & Full route \\
\hline V & $0.8(0.5)$ & $2.8(178)$ & $2.9(183)$ \\
\hline HM & $14.4(9.0)$ & $2.1(134)$ & $2.0(125)$ \\
\hline D & $4.8(3.0)$ & $1.3(85)$ & $1.2(79)$ \\
\hline $\mathbf{1}$ & $8.0(5.0)$ & $0.9(57)$ & $0.9(55)$ \\
\hline A & $2.4(1.5)$ & $1.6(102)$ & $1.5(97)$ \\
\hline L & $2.4(1.5)$ & $5.1(319)$ & $4.5(284)$ \\
\hline R & $0.5(0.3)$ & $4.6(295)$ & $4.7(303)$ \\
\hline
\end{tabular}




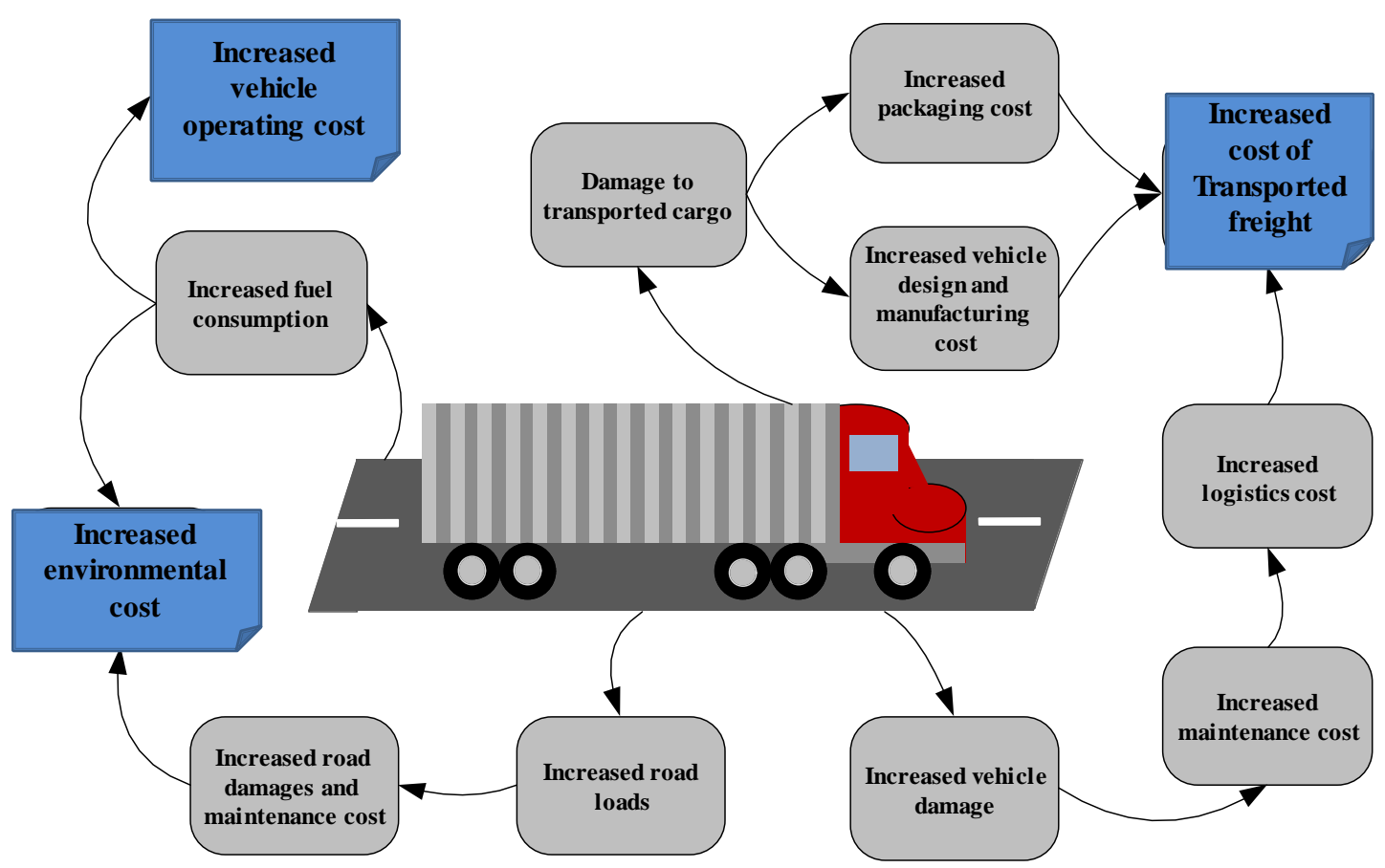

FIGURE 1 Potential effects of deteriorating road quality on the broader economy $(1,6)$. 


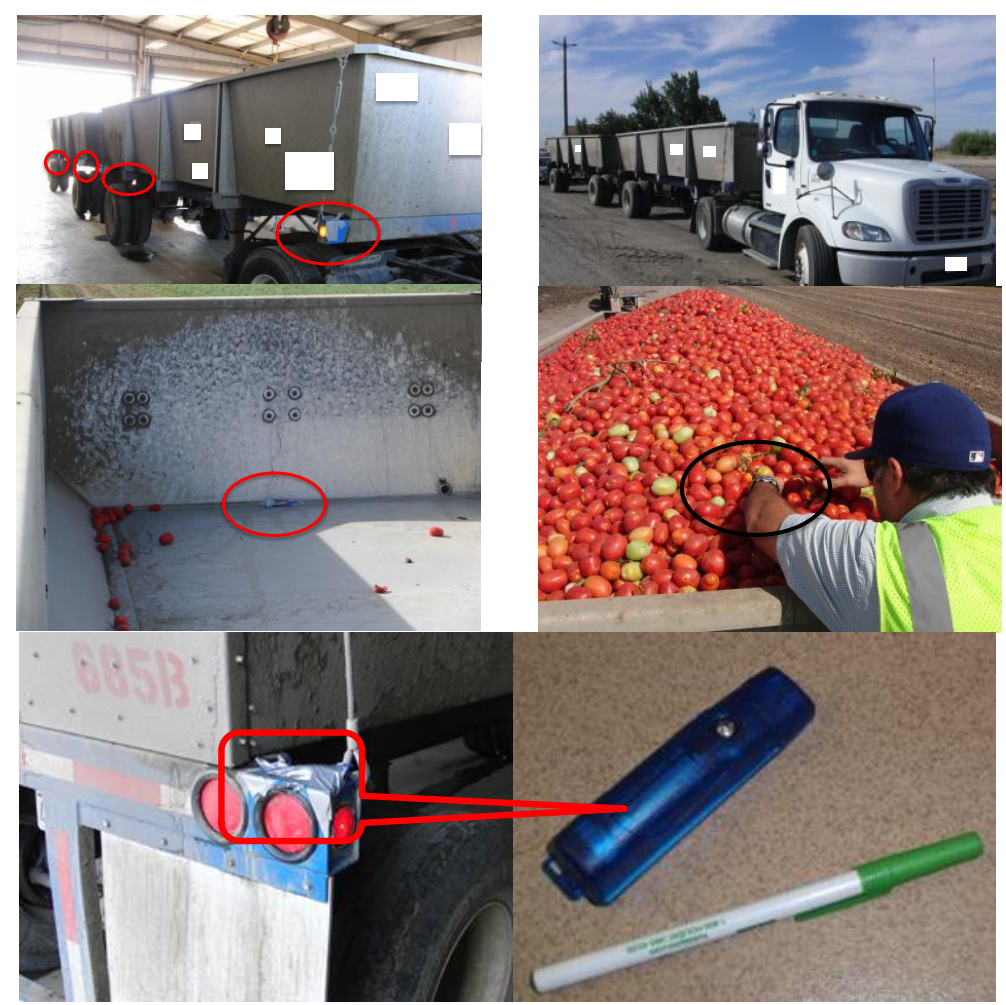

FIGURE 2 Typical Company A truck used for tomato transport showing location of sensors on the truck for field work. 


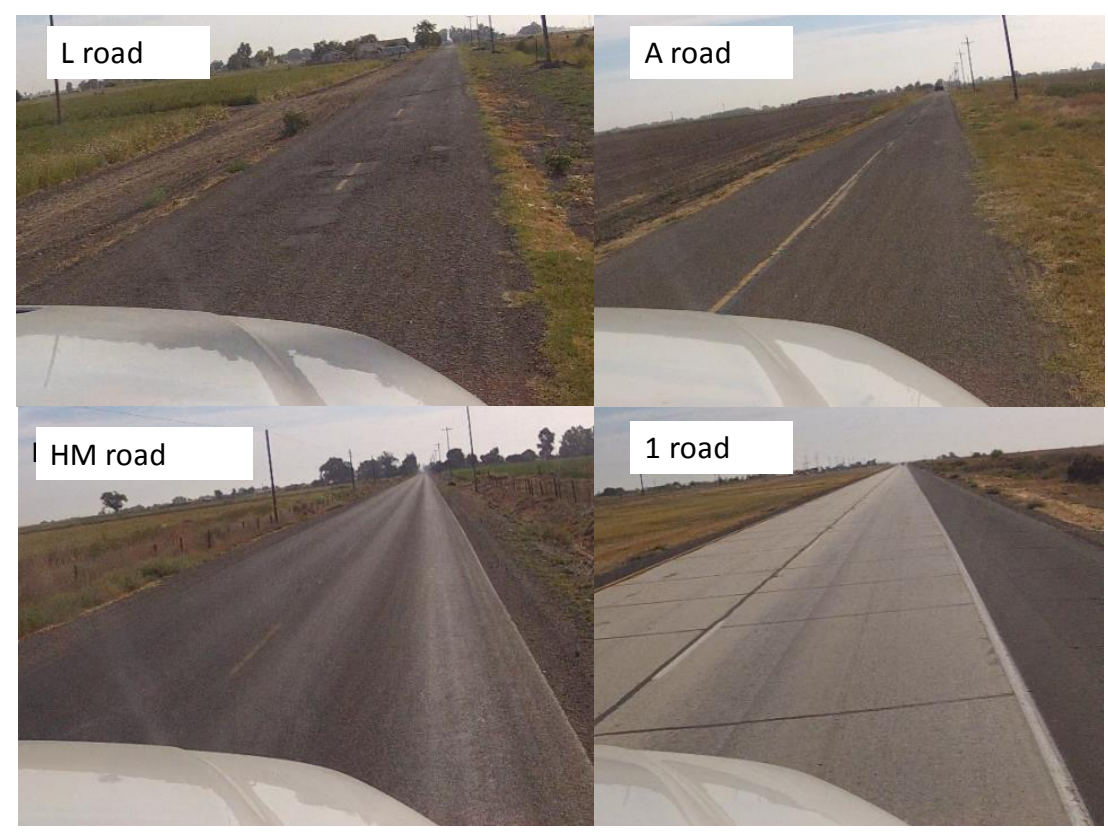

FIGURE 3 Typical Company A routes. 


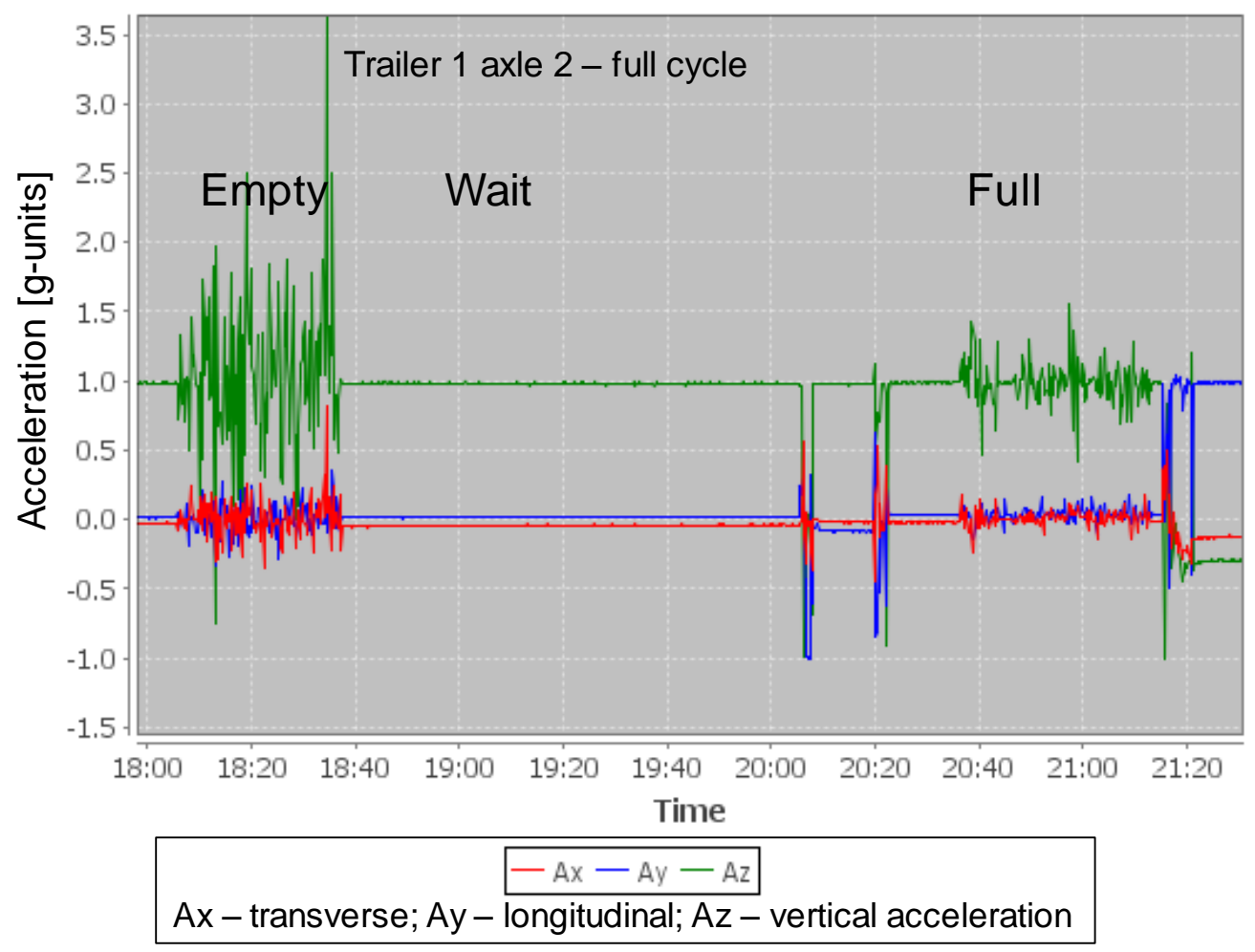

FIGURE 4 Typical accelerometer outputs. 
Truck drive

$2^{\text {nd }}$ trailer front

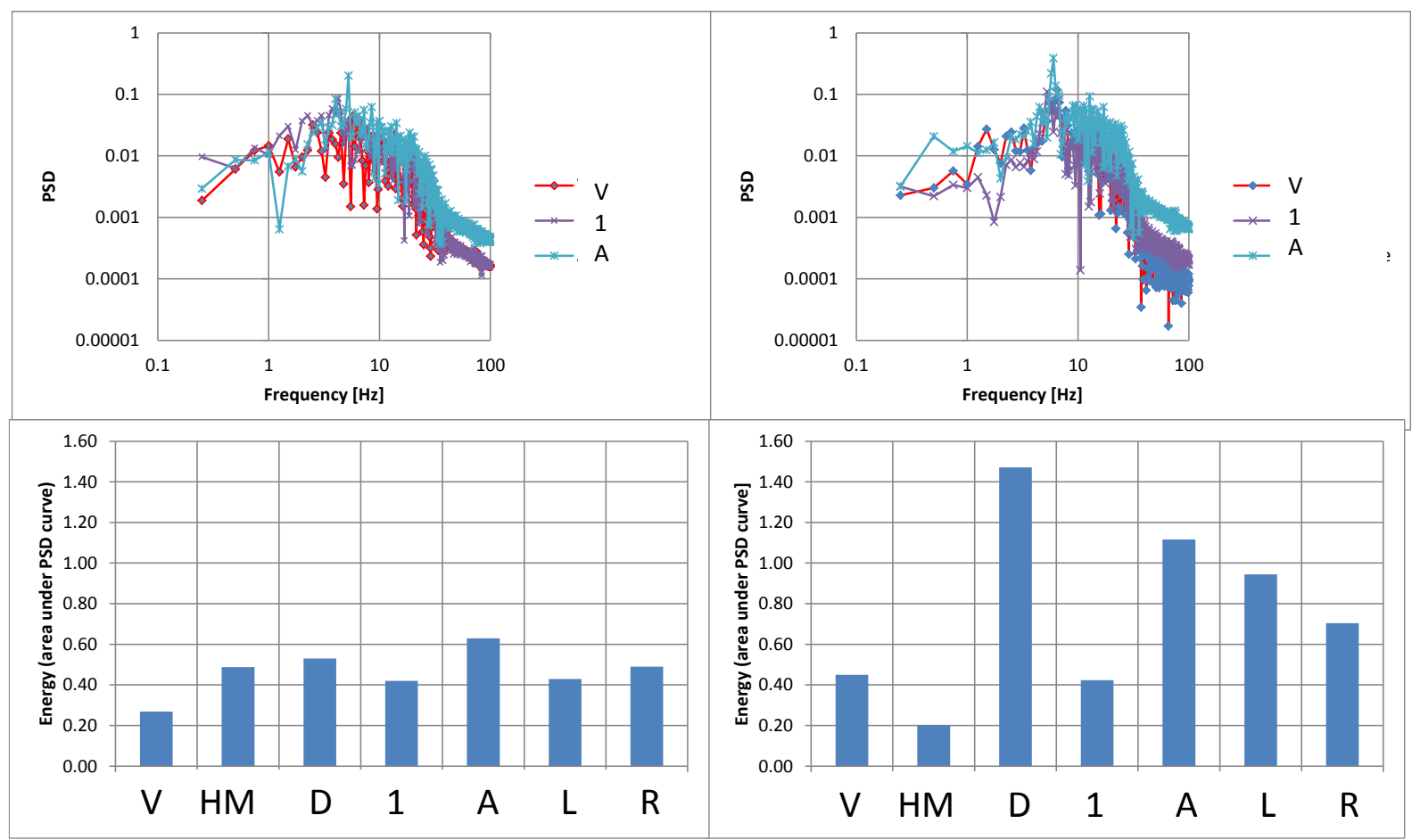

FIGURE 5 Typical PSD analysis output based on accelerometer data. 


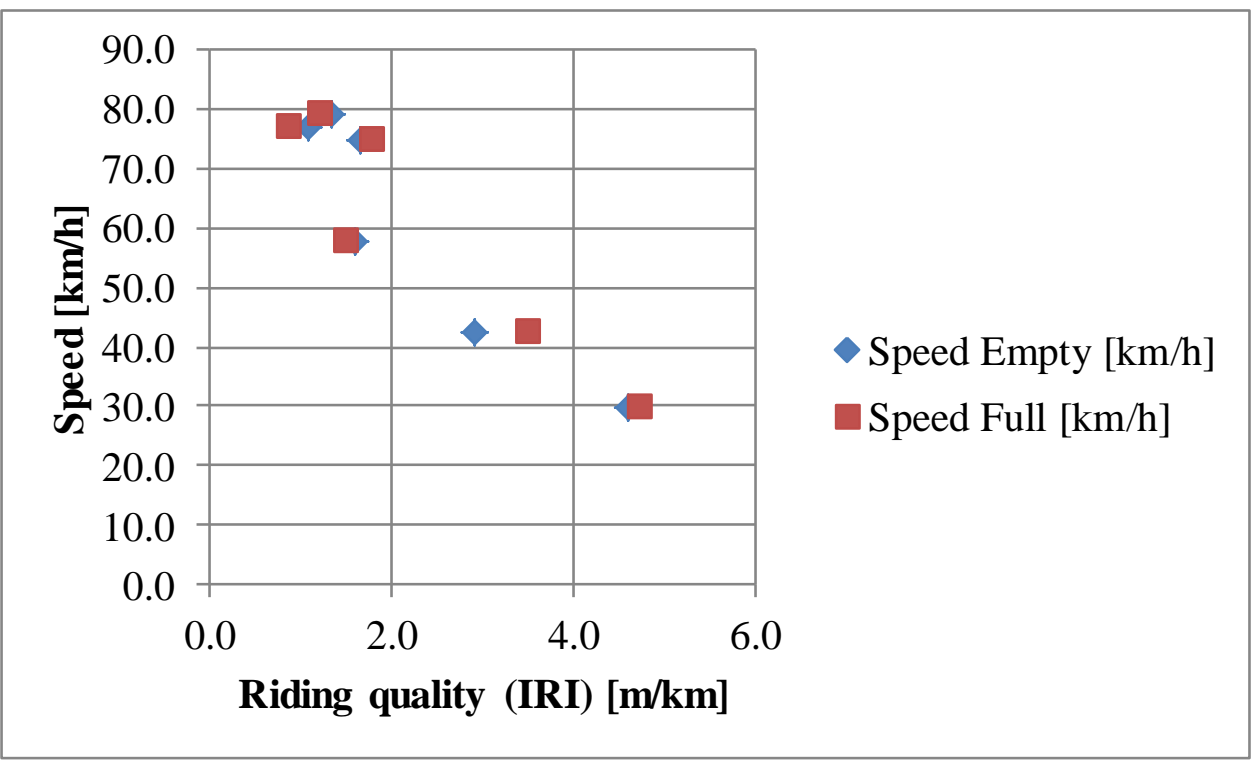

FIGURE 6 Relationship between truck speed and riding quality. 


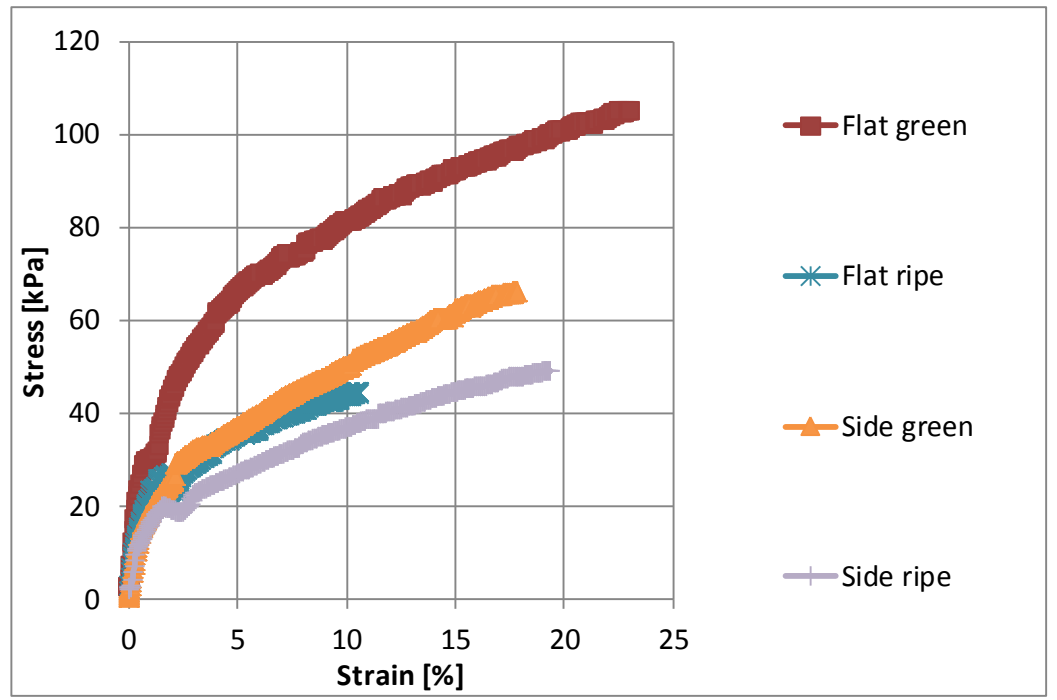

FIGURE 7 Simplified stress/strain behavior of four main groups of tomato stiffness data. 


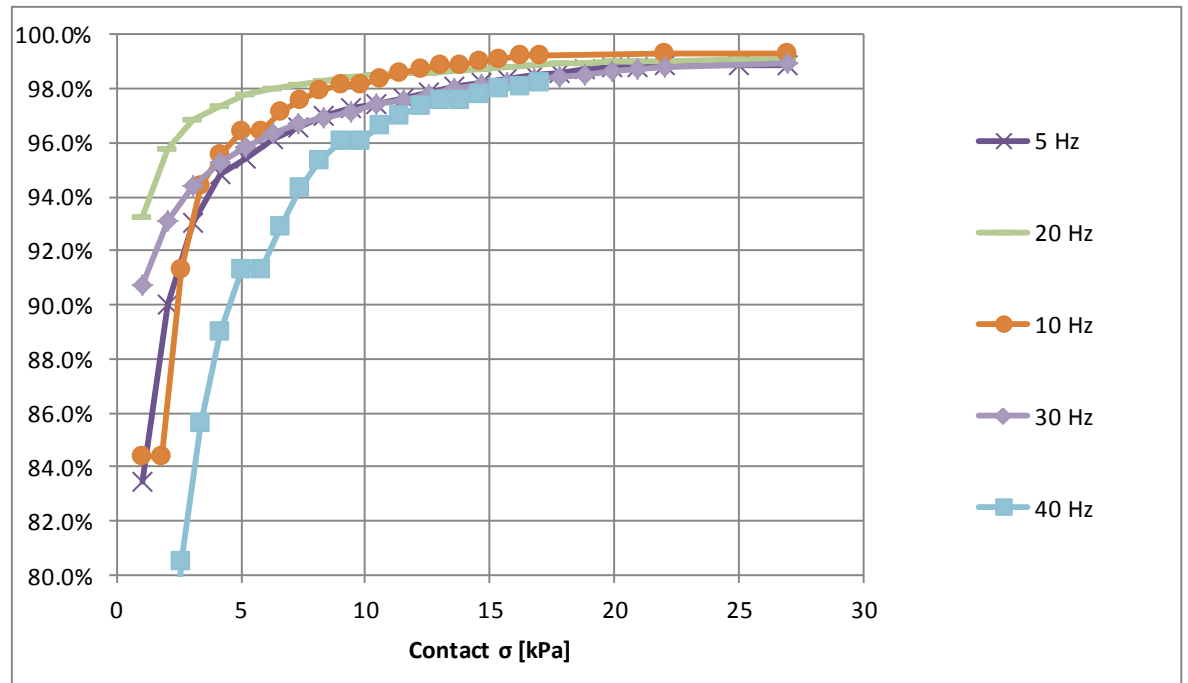

FIGURE 8 Cumulative contact stress distribution in-between tomatoes during tests for different dominant frequencies. 


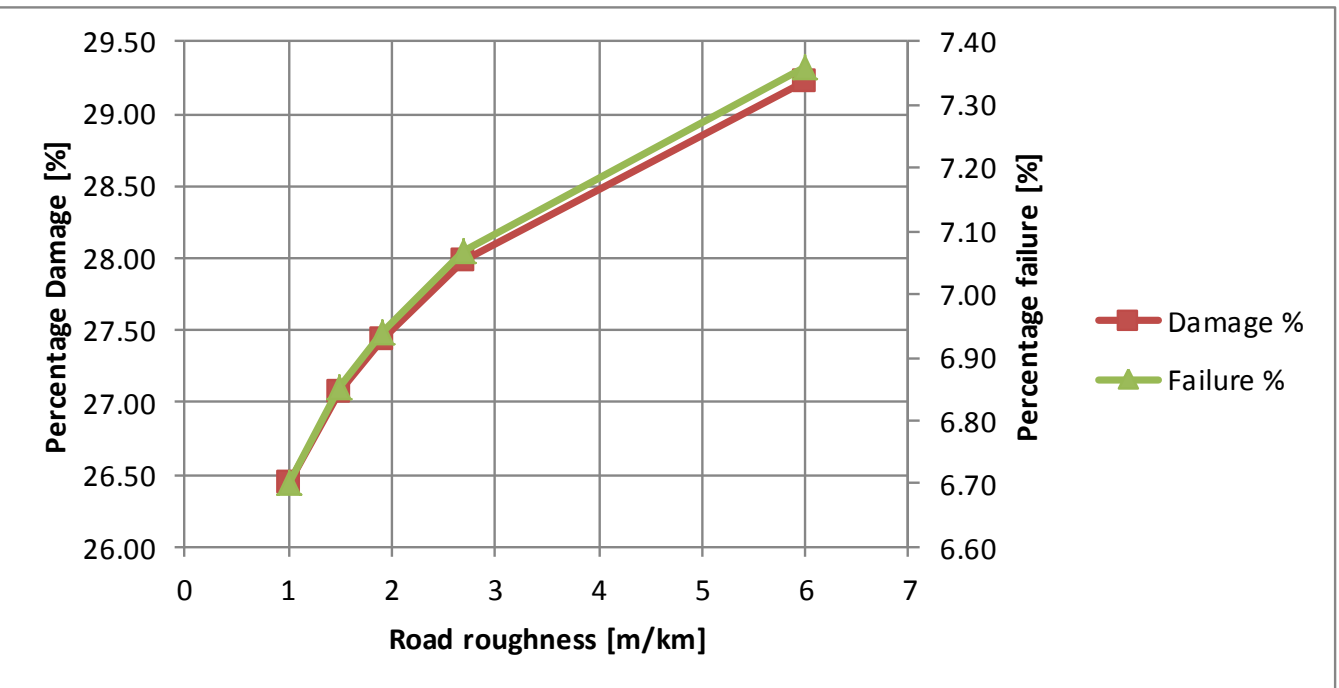

FIGURE 9 Relationship between damage and failure levels and road riding quality. 